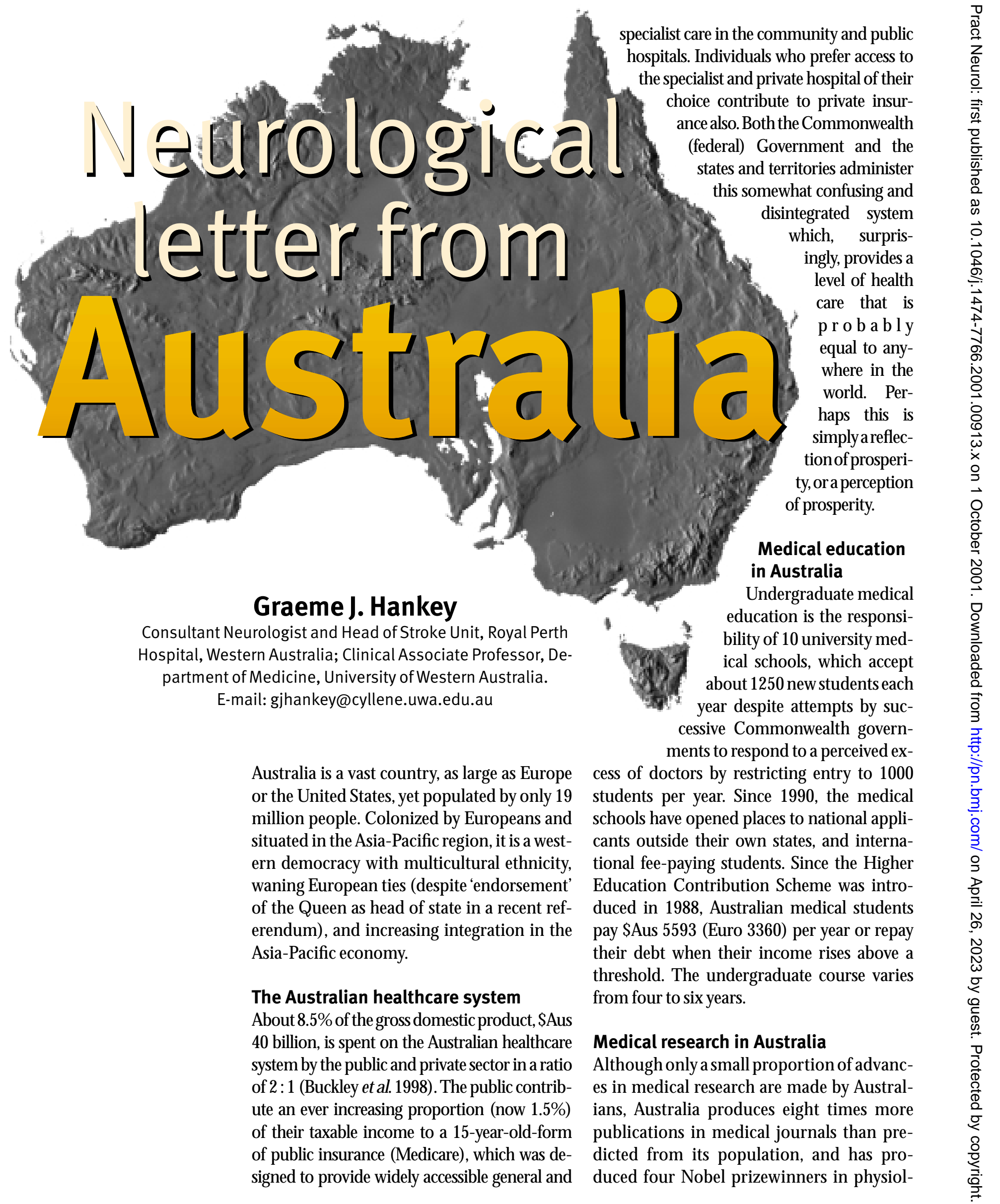


ogy or medicine: Howard Florey (clinical use of penicillin); M acfarlane Burnet (clonal selection theory in immunology); John Eccles (neural synapses); and Peter Doherty (restriction of cellular immunity) (Buckley et al. 1998). Perhaps another may be Barry $M$ arshall who was my medical registrar in 1982 when I was a resident medical officer and (with John Warren) discovered the role of Helicobacter pylori in peptic ulcers two years later (1984).

\section{Neurology in Australia}

Neurology in Australia has blossomed in the past four decades, such that there are now about 14 neurologists per million population and each capital city is served by at least one academic department of neurology (Eadie 1994).

TheAustralian Association of N eurologists (AAN) has morethan 500 members, of which about 250 are practising neurologists, and the other half are neuroscientists, trainees, research fellows, and retired and honorary members. Of those in clinical practice, about half are private practitioners with part-time appointments at a major public teaching hospital, a quarter are salaried staff specialists, and the remainder academic staff and private practitioners attached to district or private hospitals.

The AAN is represented by council, 11 committees (e.g. coretraining, advisory to the Royal Australian College of Physicians, practiceguidelines) and fivestate education committees.

It is a requirement of AAN trainees that after internship, at least threeyears training in General M edicine, and success in the first part examination of the Fellowship of the Royal Australasian College of Physicians, they embark on at least threeyears of neurology training, of which at least one year must be in a different centre, preferably overseas. For decades now, AAN trainees have enjoyed theopportunity of applying for an overseas training position offered annually by the M ayo Clinic, USA; the National Hospital, Queen Square, London, UK; and the Radcliffel nfirmary, OXford, UK. Here, many of us have had the fortune to meet special people, make lifelong friends, consolidate our sound general med- ical and neurology training, learn new and innovative aspects of clinical neuroscience, and return home the richer as neuroscientists, teachers, researchers, and people; and the poorer financially (at least for a while).

We all try to meet at least annually at the three day Annual Scientific M eeting (ASM) of the AAN, which is devoted mainly to presentations of basic and clinical research in the neurosciences. In the last decade, a number of specialist neurological groups/ societies have emerged, such as Stroke, Epilepsy, Neuro-ophthalmology, Neuro-otology, N euromuscular, M ovement Disorders, and Headache, which also meet annually, and sometimesin conjunction with theASM of the AAN .

In 1963theAAN began publishing theproceedings of its ASM $s$ as the Proceedings of the Australian Association of Neurologists, under the editorship (for the next nine years) of its then President, the lateE Graeme Robertson. All issues subsequently featured the waratah insigne of the AAN on the front cover. In 1977, when Professor John Tyrer was Editor (1973-85),AdisPressbecamepublisher of the Proceedings (until 1990) and the name was changed to Clinical and Experimental Neurology. Professor M ervyn J Eadie assumed editorship of Clinical and Experimental N eurology in 1985 and continued until 1994 when the AAN accepted theinvitation of the N eurosurgical Society of Australia to link itself with the new Pacific rim based Journal of Clinical N euroscience edited by Professor Andrew Kaye. All members of the AAN now receive the bimonthly publication of the Journal of Clinical Neuroscience. Wenow look forward to subscribing to a complementary review journal of Neurology, which will fill the vacancy between scientific articles that none of us has time to read or to try to understand, and the constant stream of biased rubbish that is imposed upon us by pharmaceutical company representatives. Will this be Practical N eurology?

\section{References}

Buckley P, M arley J, Robinson J et al. (1998) Australia. Lancet, 351, 1569-78.

M orris] \& EadieM , (1994) A Directory of Neurology in Australia. Merino Lithographics Pty Ltd, Australia. 